\title{
Tissue distribution of Diablo/Smac revealed by monoclonal antibodies
}

\author{
A Tikoo*,1, L O’Reilly ${ }^{1}$, CL Day ${ }^{2}$, AM Verhagen ${ }^{1}$, M Pakusch ${ }^{1}$ \\ and DL Vaux ${ }^{1}$ \\ 1 The Walter and Eliza Hall Institute of Medical Research, Post Office Royal \\ Melbourne Hospital, VIC 3050, Australia \\ 2 Biochemistry Department, University of Otago, PO Box 56, 710 Cumberland \\ Street, Dunedin, New Zealand \\ * Corresponding author: A Tikoo, The Walter and Eliza Hall Institute of Medical \\ Research, Post Office Royal Melbourne Hospital, VIC 3050, Australia. \\ Tel: +61 39345 2548; Fax: +61 39347 0852; E-mail: tikoo@wehi.edu.au
}

Received 5.12.01; revised 22.1.02; accepted 23.1.02

Edited by G Cohen

\begin{abstract}
Diablo/Smac is a mammalian pro-apoptotic protein that can antagonize the inhibitor of apoptosis proteins (IAPs). We have produced monoclonal antibodies specific for Diablo and have used these to examine its tissue distribution and subcellular localization in healthy and apoptotic cells. Diablo could be detected in a wide range of mouse tissues including liver, kidney, lung, intestine, pancreas and testes by Western blot analysis. Immunohistochemical analysis found Diablo to be most abundant in the germinal cells of the testes, the parenchymal cells of the liver and the tubule cells of the kidney. In support of previous subcellular localization analysis, Diablo was present within the mitochondria of healthy cells, but released into the cytosol following the induction of apoptosis by UV.

Cell Death and Differentiation (2002) 9, 710-716. doi:10.1038/ sj.cdd. 4401031
\end{abstract}

Keywords: Diablo; Smac; apoptosis; tissue; distribution; antibodies

Abbreviations: mAbs, monoclonal antibodies; IAPs, inhibitor of apoptosis proteins; BIR, baculoviral IAP repeat; s.c., subcutaneous; i.p., intraperitonealy; i.v., intravenously; FITC, fluorescein-isothiocyanate; HA, epitope (YPYDVPDYA) tag; HA Diablo, epitope HAtagged Diablo protein; IP, immunoprecipitation; IF, immunofluorescence; WB, Western blotting; FACS, fluorescence-activated cell sorter

\section{Introduction}

Apoptosis in insects and vertebrates can be controlled by inhibitor of apoptosis proteins (IAPs) that act by directly binding to activated caspases. In Drosophila, the IAPs (DIAP1 and DIAP2) are antagonized by three pro-apoptotic proteins, Grim, HID and Reaper, which bind to them, thereby displacing the active caspases. ${ }^{1-4}$ In mammals, Diablo/Smac was the first protein shown to bind and antagonize IAPs. ${ }^{5,6}$ Recently,
$\mathrm{HtrA2}$, another mammalian protein, that has an $\mathrm{N}$-terminus similar to that of Grim, Reaper, HID and Diablo, has been shown to bind and antagonize IAP function. ${ }^{7,8,9,10}$ Unlike Grim, HID and Reaper, Diablo/Smac localizes to the intermembrane space of the mitochondria in healthy cells. ${ }^{5,6}$ Upon receipt of certain apoptotic stimuli, Diablo is released from the mitochondria, and in the cytosol it is able to bind and antagonize IAPs such as MIHA/XIAP. 5,6

Diablo is synthesized in the cytoplasm as a larger precursor protein with an $\mathrm{N}$-terminal mitochondrial targeting peptide that is removed upon importation into the mitochondria. 5,6 This processing produces an $\mathrm{N}$-terminus of Diablo beginning with the residues AVP... that resembles the N-termini of Grim, Reaper and HID, which are critical for their activity. ${ }^{11,12-14}$ It is via these $\mathrm{N}$-terminal residues that these pro-apoptotic proteins bind to the core of the baculoviral IAP repeat (BIR) domains of IAPs. ${ }^{11,12,14}$ Through its interaction with MIHA/XIAP, Diablo can promote apoptosis by removing inhibition of MIHA/XIAP on processed caspases 3,7 and $9 .^{11,15,16}$

To determine where Diablo acts we wished to determine its tissue localization. To do this we have generated a series of monoclonal antibodies (mAbs) that can be used in tissue immunoblotting and histochemistry. Our studies show that Diablo is present in cell lines of different kinds and is detectable by immunohistochemistry in the testes, kidney and liver.

\section{Results}

\section{Characterization of the monoclonal antibodies}

Immunization of rats with mouse recombinant Diablo followed by fusion of spleen cells with the myeloma cell line SP2/0 yielded several hybridoma clones producing mAb specific for Diablo. The hybridoma clones secreting the $\mathrm{mAb}$, against Diablo, were identified by flow cytometric analysis of 293T cells over-expressing HA Diablo (see Materials and Methods). Figure $1 \mathrm{~A}$ is the staining profile of the transfected 293T cells incubated with secondary antibody alone (dotted line) or together with hybridoma supernatant which showed no immunoreactivity to Diablo (solid line). Hybridoma clones producing mAb specific for Diablo yielded a profile (Figure 1C,D) similar to the one produced when anti-HA antibody was used to detect the overexpressed HA Diablo (Figure 1B), which serves as a positive control. From an initial screen of 2000 hybridoma cultures, 20 anti-Diablo mAb generating hybridoma clones giving a profile similar to Figure 1C,D were selected for further analysis. Here we report characterization of two selected $\mathrm{mAbs}, 10 \mathrm{G} 7$ and $9 \mathrm{H} 10$. These mAbs were isotyped to be rat IgG2a, and were purified using protein-G affinity columns. They were tested for applications including Western blot 


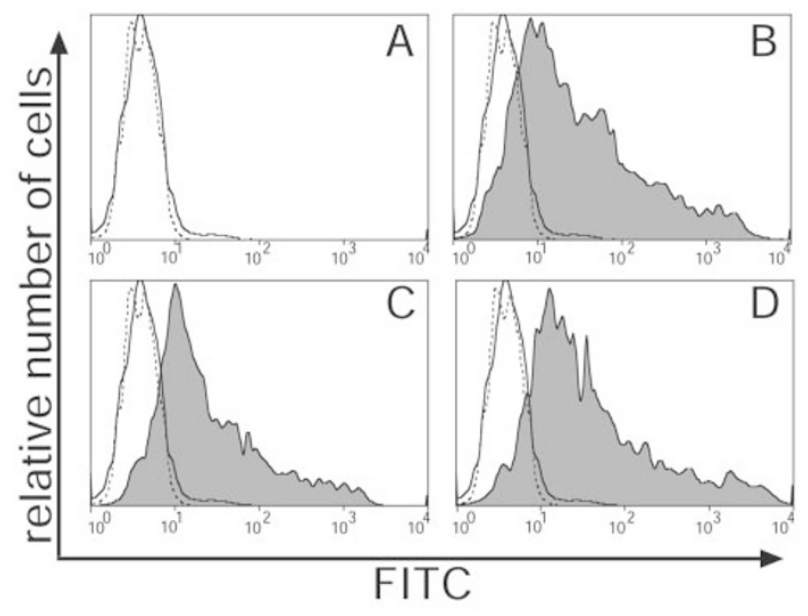

Figure 1 Screening of hybridoma clones for Diablo specific monoclonal antibodies (mAbs) by flow cytometry using HA Diablo expressed in 293T cells. 293T cells were transfected with vector encoding HA Diablo and stained with FITC-labelled secondary goat anti-rat IgG alone (dotted line in A) after incubation with supernatants from hybridoma clones not secreting the mAb (solid line in A), after incubation with anti-HA antibody (B) or after incubation with supernatants from hybridoma clones secreting anti-Diablo mAbs ( $\mathbf{C}$ and D). C-D represent profile for the hybridoma clones producing $m A$ bs that can detect Diablo in the cells over-expressing HA Diablo. For comparison the negative profiles shown in $\mathbf{A}$ have been super imposed in $\mathbf{B}-\mathbf{D}$

analysis, immunohistochemistry, immunocytochemistry and immunoprecipitation (Table 1).

\section{The specificity of $10 \mathrm{G} 7$ and $9 \mathrm{H} 10$}

Equal amounts of protein from various human and mouse cell lines was analyzed directly or after immunoprecipitation using either 10G7 or 9H10. Lysate from 293T cells over-expressing $\mathrm{HA}$ Diablo and probed with either of the $\mathrm{mAb}$ was used as size control.

Western blot and immunoprecipitation analysis of lysates from various cell lines demonstrated that $10 \mathrm{G} 7$ recognizes both human and mouse Diablos (Figures $2 \mathrm{~A}$ and 3 ). The membrane was re-probed with anti-HA antibody to detect the over-expressed HA Diablo in lanes 6 and 7 (Figure 2B). Due to over-expression and possible overloading of the mitochondrial processing mechanisms, the transfected cells show a band for unprocessed Diablo in addition to processed HA Diablo band (23 kD), which is similar to the endogenous Diablo. The processed HA Diablo runs slower than the endogenous Diablo presumably due to addition of the 9 residue HA tag. Under similar conditions $9 \mathrm{H} 10$ is specific for mouse Diablo (Figure 4A). 9H10 did not detect Diablo in the three human cell lines studied here. Equal protein loading from all cell lines was demonstrated by re-probing the blots with antibody specific to Hsp70 (Figures 2C and 4B).

\section{Expression of Diablo in mouse tissues}

Endogenous mouse Diablo was detected in various tissues by Western blot and immunoprecipitation (Figures $5 \mathrm{~A}$ and 6 ) using $9 \mathrm{H} 10$. Testes showed the highest level of expression,
Table 1 Summary of characteristics for Diablo mAbs: $10 \mathrm{G} 7$ and $9 \mathrm{H} 10$

\begin{tabular}{lccc}
\hline Clone name & Isotype & Applications & Specificity \\
\hline $10 \mathrm{G} 7$ & IgG2a & WB, IP, IF, & human and \\
& FACS and Elisa & mouse \\
$9 \mathrm{H} 10$ & IgG2a & WB, IP, IF, & mouse \\
& \multicolumn{3}{c}{$\begin{array}{c}\text { FACS, Elisa and } \\
\text { tissue } \\
\text { histochemistry }\end{array}$} \\
\hline
\end{tabular}

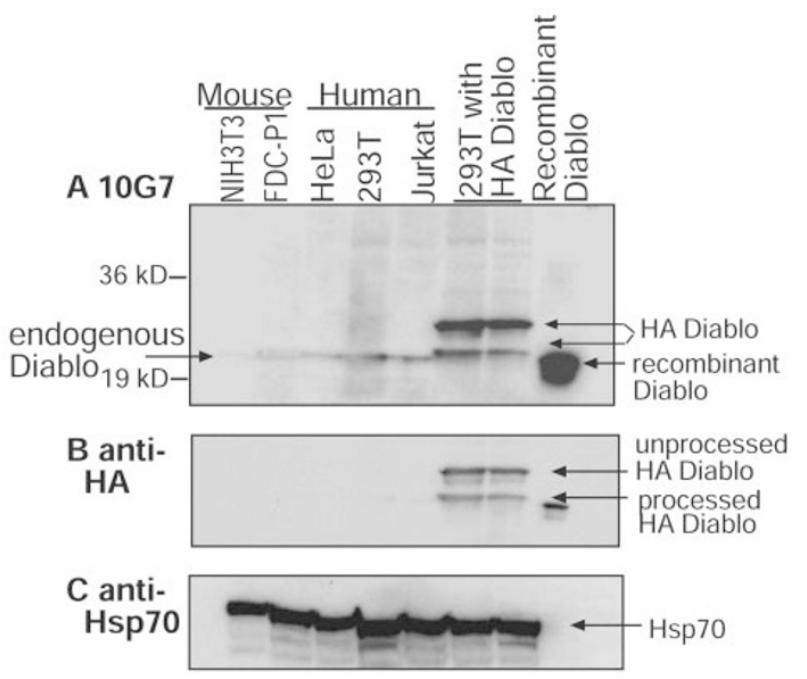

Figure 2 Detection of endogenous Diablo by Western analysis using 10G7. (A) Total protein (150 $\mu \mathrm{g}$ per lane) from mouse (lanes 1-2) and human (lanes $3-5$ ) derived cell lines was used to detect endogenous Diablo by Western blot (lanes 1-5). Lanes 6 and 7 contain whole cell lysate from 293T cells overexpressing HA Diablo. Bacterially produced recombinant protein was used in lane 8. (B) The membrane was re-probed with anti-HA antibodies to reveal HA Diablo in lanes 6 and 7. In addition to processed Diablo, unprocessed Diablo can also be detected in 293T cells transfected with HA Diablo construct. (C) Immunoblotting with antibody to Hsp 70 indicated protein loading

followed by moderate expression in kidney, liver, intestine, lung and pancreas (Figures 5A and 6). Heart also showed a low level of Diablo (although not obvious in the figure shown here). There was no visible Diablo expression in brain (Figures 5A and 6). In other tissues such as thymus, spleen and skeletal muscle Diablo was not detectable by Western analysis (data not included).

The expression pattern of Diablo in mouse tissues was also investigated by immunohistochemistry using $9 \mathrm{H} 10$ $\mathrm{mAb}$ (Figure 7). Consistent with the results obtained by immunoblotting, Diablo was most abundant in the testes. Intense Diablo immunostaining was observed in the germinal epithelium of seminiferous tubules but not in the Leydig cells of interstitium. Staining was intense in the cytoplasm of primary spermatocytes, secondary spermatocytes and spermatids (Figure 7C). In the kidney, Diablo was most abundant in the ductal epithelia of the cortex but no immunoreactivity was detected in the glomeruli (Figure 7A). In the liver, the expression of Diablo was restricted to hepatocytes (Figure 7B). 


\section{Diablo localizes to the mitochondria}

HeLa cells were transiently transfected with the full-length mouse Diablo pEF construct (see Materials and Methods) and immunofluorescence staining was performed using $9 \mathrm{H} 10$ followed by detection with FITC-labelled secondary antibody. The mitochondria and nuclei were co-stained using Mito Tracer Red and DAPI respectively. Analysis was performed using confocal microscopy. While the mitochondria and nuclei of all cells were stained, $9 \mathrm{H} 10$ only detected mouse Diablo in the cells transfected with the mouse Diablo construct. Under the conditions used here, $9 \mathrm{H} 10$ does not react with endogenous human Diablo in HeLa cells (Figure 8A,B). Furthermore, in healthy cells (Figure $8 \mathrm{~A}$ ) most of the Diablo co-localized within the mitochondria whereas after exposure to UV, Diablo was present throughout the cell (Figure 8B). Using 10G7, distribution of endogenous human Diablo in

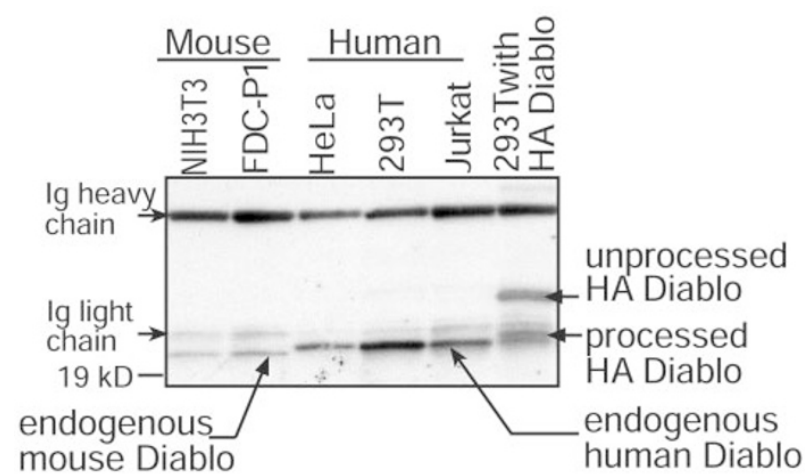

Figure 3 Immunoprecipitation of endogenous Diablo from cell lines using 10G7. Equal amounts of protein from mouse (lanes 1-2) and human cell lines (lanes 3-5) were immunoprecipitated using 10G7, subjected to electrophoresis, blotted and detected with polyclonal rabbit antiserum to Smac. Lane 6 contains protein from 293T cells over-expressing HA Diablo that was immunoprecipitated with $10 \mathrm{G} 7$

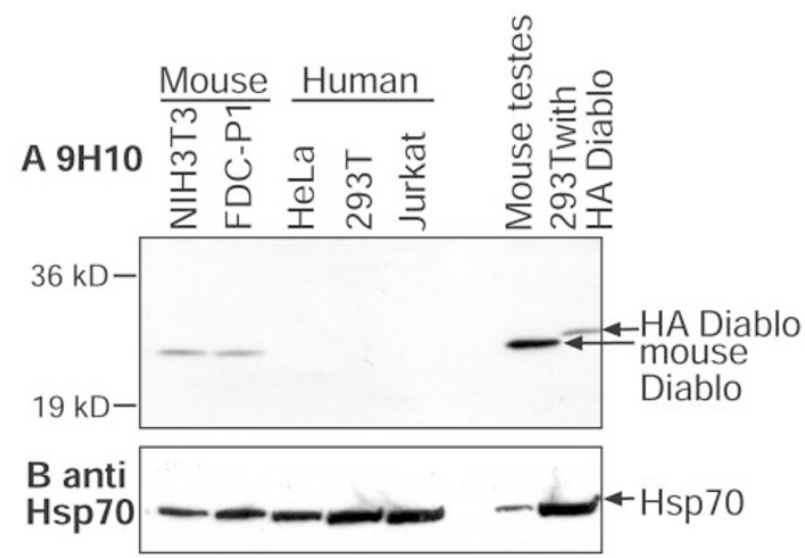

Figure 4 Detection of endogenous Diablo from cell lines by Western blotting using $9 \mathrm{H} 10$. (A) $150 \mu \mathrm{g}$ of total protein from mouse (lanes 1-2) and human cell lines (lanes $3-5$ ) were probed with $9 \mathrm{H} 10$. Whole cell lysates from mouse testes (lane 7) and 293T cells over-expressing HA Diablo (lane 8) were used as positive controls. (B) The membrane was re-probed with anti Hsp 70 to demonstrate protein loading
HeLa cells showed a punctate expression consistent with mitochondrial localization (data not shown).

\section{Discussion}

Full-length Diablo (27 kD) undergoes N-terminal processing to yield a smaller $(21 \mathrm{kD})$ protein. ${ }^{6}$ As seen in Figures $2 \mathrm{~A}$ and 3 , endogenous mouse Diablo seems to run slightly faster than endogenous human Diablo even though Diablo in the two species has a similar predicted molecular weight and $89 \%$ identity.

The amounts of Diablo protein in mouse tissues corelated well with the mRNA levels as previously described $^{5,6}$ except in the heart, where the amount of Diablo protein seems much lower than that expected from the abundance of mRNA. Testes showed the highest levels

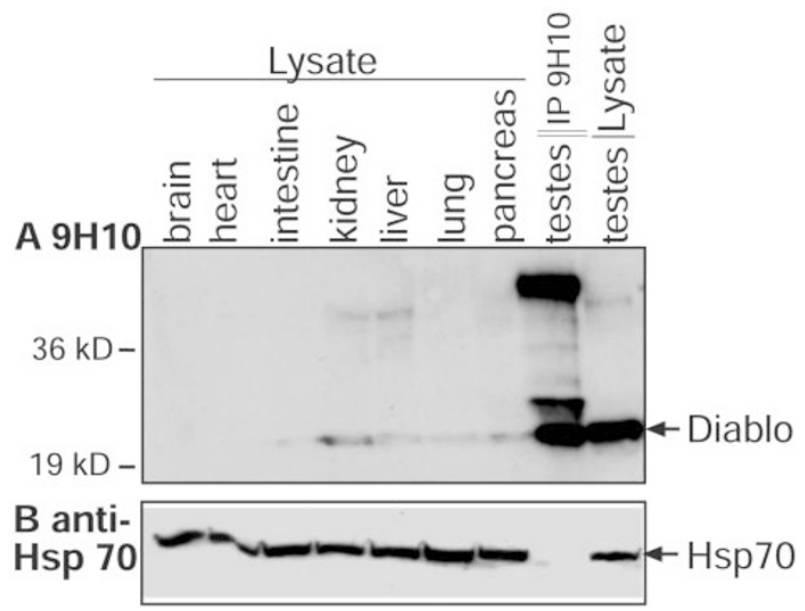

Figure 5 Detection of endogenous Diablo in mouse tissues using 9H10. (A) $300 \mu \mathrm{g}$ of total protein from various tissues was analyzed by direct Western blot using 9H10 (lanes 1-7 and 9). For size comparison, lane 8 contains Diablo immunoprecipitated from mouse testes using $9 \mathrm{H} 10$ followed by Western blot with the same antibody. In addition to detection of endogenous Diablo, bands for IgG heavy and light chain can also be seen in lane 8. (B) An identical gel was run for probing with anti $\mathrm{Hsp} 70$ to indicate protein loading

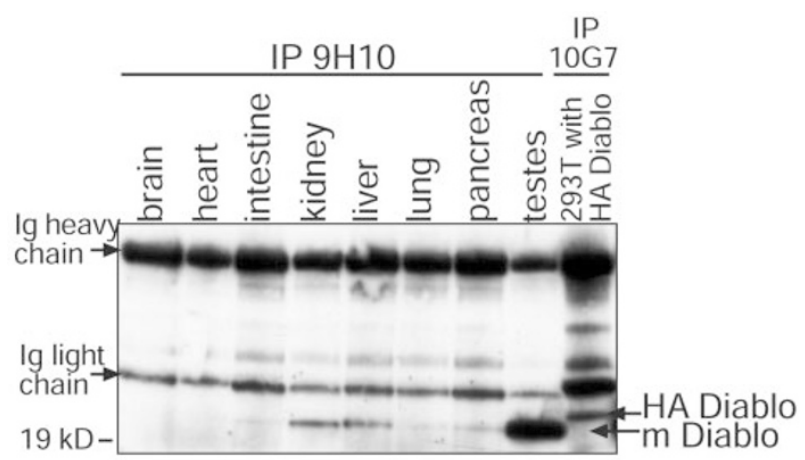

Figure 6 Immunoprecipitation of Diablo from mouse tissues using $9 \mathrm{H} 10$. Mouse tissue proteins $(500 \mu \mathrm{g})$ were immunoprecipitated using $9 \mathrm{H} 10$ (lanes $1-8$ ) and detected with $9 \mathrm{H} 10$. As a positive control, lane 9 contains Diablo immunoprecipitated with 10G7 from 293T cells transfected with HA Diablo construct prior to detection by $9 \mathrm{H} 10$ 

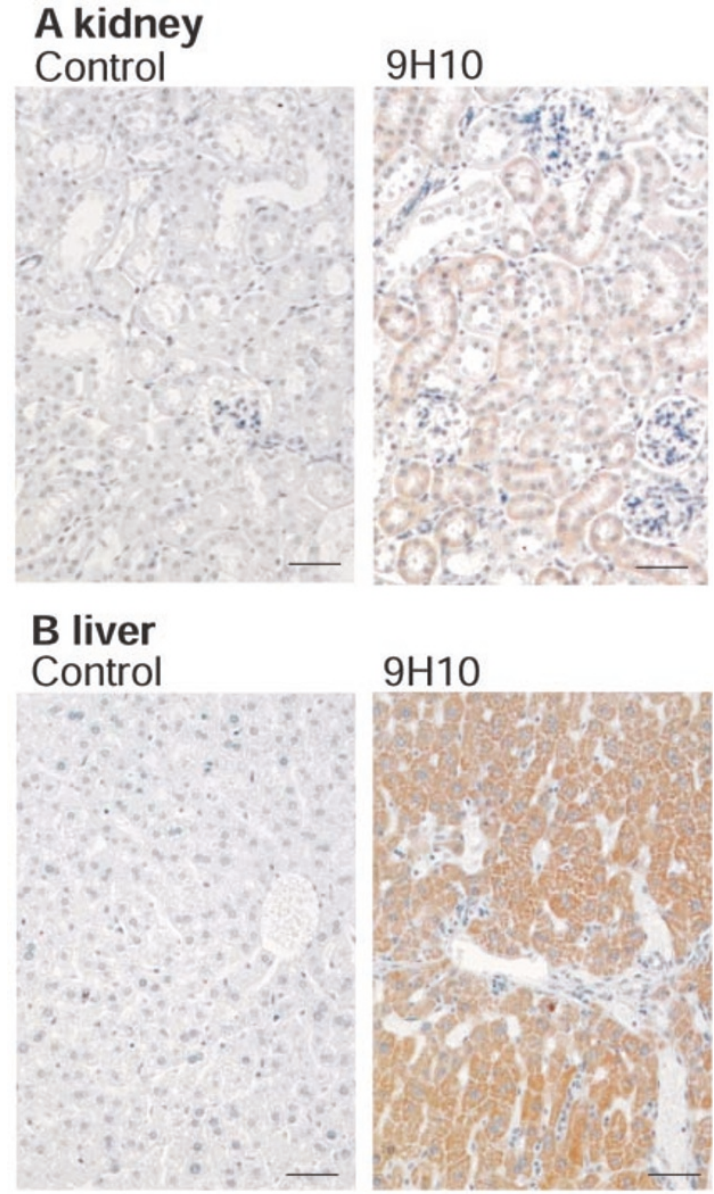

\section{C testes}

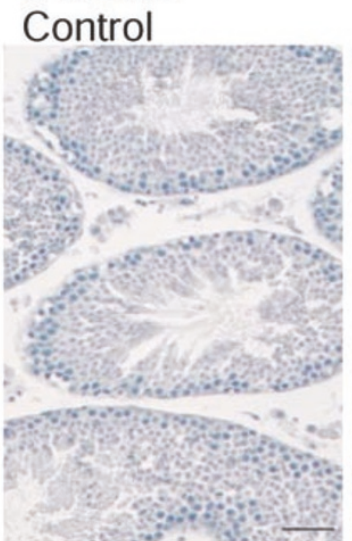

$9 \mathrm{H} 10$

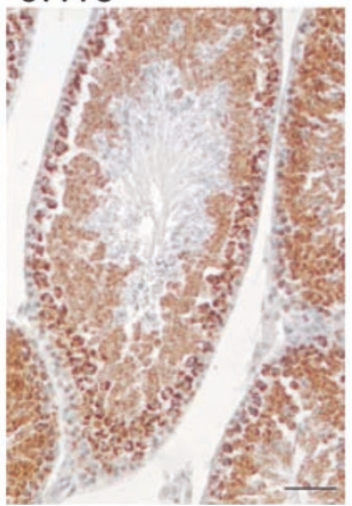

Figure 7 Tissue expression of mouse Diablo as revealed by immunohistochemistry. Using $9 \mathrm{H} 10$ endogenous mouse Diablo was detectable in the kidney (A), liver (B) and testes (C). Biotinylated goat anti-rat IgG was used as the secondary antibody followed by detection with DAB reagent. The bar represents $200 \mu \mathrm{m}$

of Diablo protein. It is possible that high expression of proapoptotic molecules, such as Diablo, may be responsible for conferring the high sensitivity of testicular germ cells to radiation-induced apoptosis ${ }^{17,18}$ however Diablo was not abundant in the thymus, where cell turn over is also high and cells are similarly sensitive to radiation.
The pro-apoptotic activity of Diablo is mainly controlled by its localization. Diablo is produced as a precursor protein and targeted to the mitochondria by an $\mathrm{N}$-terminal targeting peptide, which is removed by proteolysis to localize Diablo to the inter-membrane space. ${ }^{5,6}$ The processed form is present in the mitochondria of healthy cells, as is cytochrome $c$, which when released can activate Apaf-1 in the cytosol, leading to activation of the apoptosome and caspases 9 and $3^{5,6,19,20}$ Processing of Diablo produces an $\mathrm{N}$-terminus beginning with the residues AVP that resembles the $\mathrm{N}$-termini of Drosophila pro-apoptotic proteins Grim, Reaper and HID that are critical for their activity. ${ }^{11-14}$ As shown in Figure 8, over-expressed mDiablo detected by mouse specific $9 \mathrm{H} 10$ localizes to the mitochondria. Endogenous human Diablo in HeLa cells, detected by $10 \mathrm{G} 7$ had the same pattern of expression as seen in the transfected cells (data not shown). Following an apoptotic stimulus such as UV radiation, Diablo is released from the mitochondria into the cytoplasm. ${ }^{5,6}$ In the cytoplasm Diablo can interact with IAPs ${ }^{5,6}$ thereby preventing them from inhibiting activated caspases. ${ }^{21-23}$

The finding that Diablo is expressed differentially among various tissue types, and the lack of correlation between levels of Diablo mRNA and protein in the heart, raises the possibility that Diablo may be under transcription and posttranslational control, in addition to being controlled by its localization within the mitochondria. Indeed, a recent publication suggests that the Diablo gene may be induced by the cytokine IFN $\gamma^{24}$

\section{Materials and Methods}

\section{Expression constructs}

Full-length mouse Diablo cDNA fused to a C-terminal HA (YPYDVPDYA) epitope tag (HA Diablo) subcloned into mammalian expression vector pcDNA3 as described previously ${ }^{6}$ was used for expression in the 293T cell line. A pEF BOS expression construct encoding untagged Diablo also described previously ${ }^{6}$ was used for expression in HeLa cells. To prepare recombinant protein, Diablo was expressed as a glutathione-S-transferase (GST) fusion protein. Nterminal deleted fragment $(1-54)$ of mouse Diablo cDNA, encoding the processed form (without the mitochondrial targeting sequence), was sub-cloned into vector pGEX-6p-3 (Pharmacia) for production of GST-Diablo in E. coli BL21.

\section{Protein expression and purification}

GST-Diablo was expressed and purified according to the previously described procedure. ${ }^{25,26}$ Briefly, the recombinant GST-Diablo protein was expressed in E. coli BL21 (DE3) following IPTG induction. The cells were lysed and protein purified by affinity chromatography using glutathione sepharose (Pharmacia). While the sample was bound to the resin, the GST-tag was removed by overnight digestion with PreScission protease (Amersham Pharmacia). Soluble Diablo was recovered from the resin and further purified by size exclusion chromatography using a Superdex 200 column. Following the purification Diablo contained five additional residues (GPLGS) attached to its $\mathrm{N}$-terminus. The purified recombinant Diablo was used to immunize the rats for production of monoclonal antibodies. 
A untreated
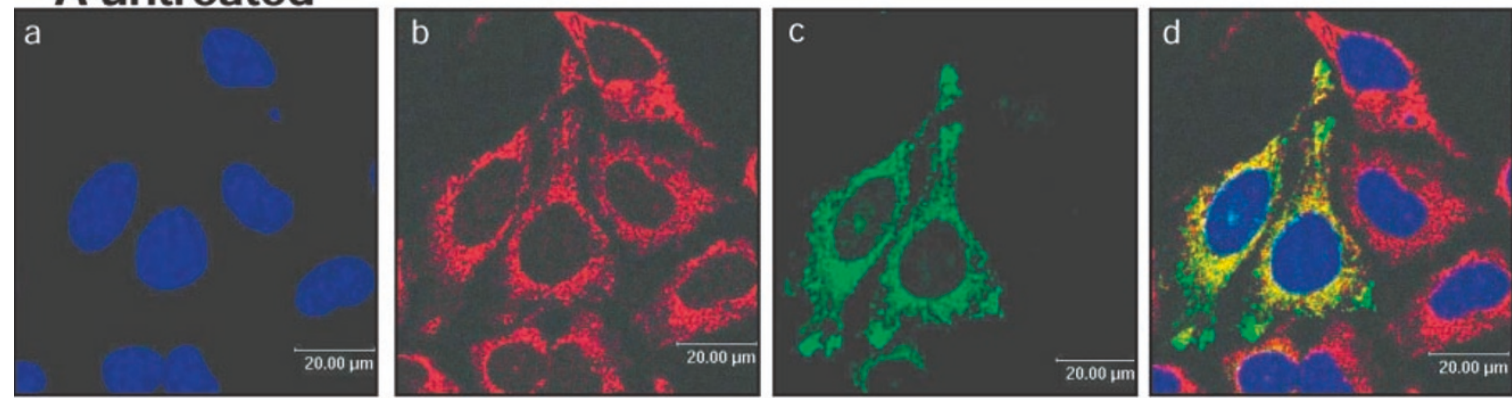

\section{B UV treated}
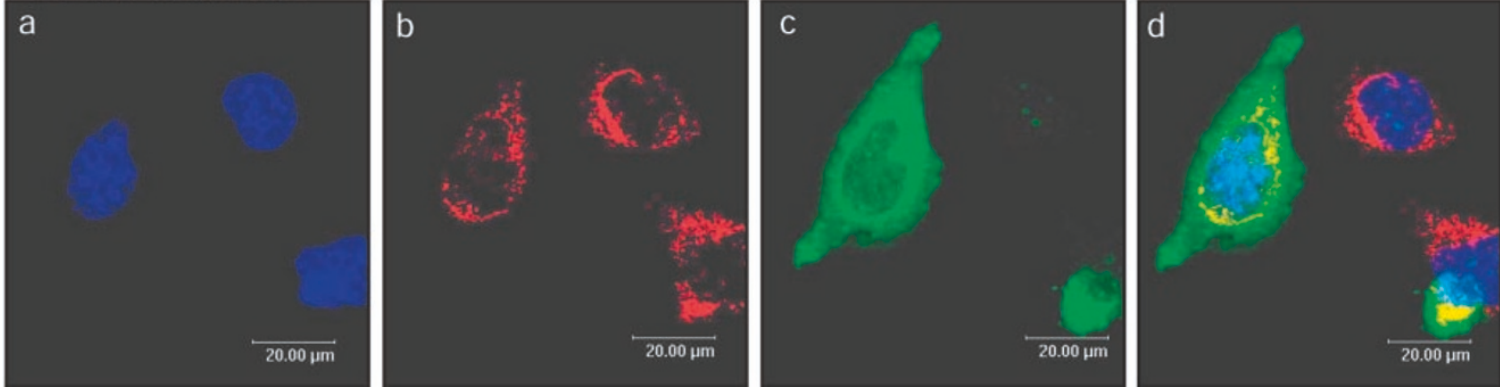

Figure 8 Localization of Diablo in HeLa cells using confocal microscopy. HeLa cells were transfected with a vector containing mouse Diablo and stained with 9H10, followed by a FITC-coupled secondary (c). Mitochondria and nuclei were co-stained using Mito Tracer Red (b) and DAPI (a). (A) In healthy cells Diablo is mainly localized to mitochondria (c,d). (B) In UV treated cells Diablo leaks out from the mitochondria (c,d)

\section{Immunization}

Wistar rats were initially immunized by subcutaneous (s.c.) injection with $100 \mu \mathrm{g}$ of purified recombinant Diablo mixed with complete Freund's adjuvant (Difco). Two subsequent boosts of the immunogen, resuspended in complete Freund's adjuvant (Difco), were injected s.c. 3 and 6 weeks after the initial injection. A final boost with recombinant Diablo dissolved in PBS was given intravenously (i.v.) and intraperitonealy (i.p.) after 4 weeks. Three days later, hybridomas were generated by fusing spleen cells from immunized rats with the SP2/0 myeloma cell line as previously described. ${ }^{27}$

\section{Hybridoma screening for antibodies to Diablo}

Hybridomas producing monoclonal antibodies to Diablo were identified and their isotype determined using a previously described screening strategy. ${ }^{27}$ Briefly, 293T cells were transiently transfected with vectors encoding HA-tagged Diablo. $5 \times 10^{5}$ transfected cells were fixed in $1 \%$ paraformaldehyde and plated into each well of 96-well tissue culture plate (Becton Dickinson, CA, USA). The cells were washed, permeabilized with $0.3 \%$ saponin (Sigma) and incubated with $100 \mu \mathrm{l}$ of hybridoma supernatants for $1 \mathrm{~h}$ on ice. Bound antibodies were revealed with fluorescein-isothiocyanate (FITC)-conjugated goat antirat $\lg G(\mathrm{H}+\mathrm{L})$ secondary antibodies (Southern Biotechnology) and detected by FACScan ${ }^{\mathrm{TM}}$ (Becton Dickinson). Antibody to the HA epitope tag (Boehringer Mannheim) was used as positive control to detect efficiency of transfection of HA Diablo construct and compare the profile of the antibody producing clones.

Hybridomas producing antibodies to Diablo were cloned twice and adapted for growth in medium containing low serum. For production of large amounts of antibodies, hybridomas were cultured for several weeks in the miniPERM classic $12.5 \mathrm{kD}$ bioreactors (VIVA SCIENCE). Antibodies were purified on a protein-G sepharose column (Pharmacia).

\section{Tissue culture and transfections}

The human embryonic carcinoma cell line 293T and mouse cell lines NIH3T3 and FDC-P1 were routinely grown in DME media supplemented with $10 \%$ FCS. FDC-P1 cells were also supplemented with IL-3. Human cell lines HeLa and Jurkat were grown in RPMI media supplemented with $10 \%$ FCS. These cell lines were used to detect endogenous Diablo by immunoprecipitation and Western analysis.

293T and HeLa cells were transfected with HA Diablo or untagged Diablo construct using Effectene ${ }^{\mathrm{TM}}$ transfection reagent (Qiagen) following the manufacturer's instructions. Forty-eight hours after transfection, the cells were used for screening the hybridoma clones and/or examining the expression of transfected Diablo constructs by immunoprecipitation, immunofluorescence and Western analysis.

\section{Western blotting and immunoprecipitation}

Various mouse organs/tissues were excised, rinsed in PBS and immediately frozen in isopentane on dry ice before homogenizing in lysis buffer at $4^{\circ} \mathrm{C}$ according to the method described previously. ${ }^{28}$ Cell lysates were prepared from various cell lines or mouse tissues using cold lysis buffer (20 mM Tris, pH 7.5, $150 \mathrm{mM} \mathrm{NaCl}, 10 \%$ Triton X-100, 10\% glycerol, 2 mM EDTA and complete protease inhibitor cocktail obtained from Roche, Mannheim, Germany). The concentration of protein was determined using Bio-Rad protein assay reagent (Bio-Rad laboratories, NSW, Australia). These lysates were then used for Western blots or for immunoprecipitation. One hundred and fifty micrograms of total protein from various cell lines was used to detect endogenous Diablo by Western blot. A minimum of $300 \mu \mathrm{g}$ of total mouse tissue protein per lane was required to detect endogenous Diablo by Western blot. Protein from the cell lysates (a minimum of $500 \mu \mathrm{g}$ from tissue total protein) was immunoprecipitated with antiDiablo $10 \mathrm{G} 7$ or $9 \mathrm{H} 10 \mathrm{mAbs}$ plus protein G-Sepharose for $1 \mathrm{~h}$. After 
extensive washing the immunoprecipitated material was eluted by boiling in sodium dodecyl sulphate-polyacrylamide gel loading buffer. Protein samples were size-fractionated on polyacrylamide gels (Gradipore), and transferred to Hybond ${ }^{\mathrm{TM}}-\mathrm{C}$ extra membranes (Amersham Life Science) by electroblotting. Non-specific binding of antibodies to membranes was blocked by incubation in $10 \%$ skimmed milk or $10 \%$ horse serum made in PBS containing $0.05 \%$ Tween- 20 . The membranes were then probed with $10 \mathrm{G} 7$ or $9 \mathrm{H} 10$ followed by HRP labelled goat anti-rat IgG (Amersham Pharmacia or Southern Biotechnology). Bound antibodies were visualized by enhanced chemiluminescence (ECL) (Amersham Pharmacia). Transfected HA Diablo was used as a size control for most of the experiments. To control for the concentration and integrity of proteins in the tissue lysates, blots were reprobed with mouse anti-Hsp70 mAb (a gift from Dr. David Huang, The Walter and Eliza Hall Institute, Melbourne, Australia). The rabbit antiserum to Diablo/Smac was kindly provided to us by Dr. Xiaodong Wang. ${ }^{5}$

\section{Tissue histochemistry}

Tissue histochemistry procedures were based on online protocols (www.protocol-online.net/immuno/immunohisto/immunohistochemistry.htm). Freshly cut mouse tissues were fixed in Histochoice (Amresco, Solon, $\mathrm{OH}$ ) for $1-3 \mathrm{~h}$ and processed for paraffin embedding followed by section cutting. Before staining the tissue sections were dewaxed and gradually rehydrated. Tissue sections were treated with $0.3 \%$ hydrogen peroxide in PBS to block the endogenous peroxidase activity. The cells were then permeabilized by incubation in $0.2 \%$ Triton $\mathrm{X}-100$ and non-specific staining was prevented by incubation with $2.5 \%$ horse serum for $1 \mathrm{~h}$ at room temperature. Sections were incubated in a humidified chamber with $9 \mathrm{H} 10$ for $1 \mathrm{~h}$ at room temperature. After washing in PBS containing $0.2 \%$ Triton X-100, tissues were incubated with HRP conjugated goat anti-rat IgG (Amersham Pharmacia). To enhance the signal, the tissues were incubated with biotinylated goat anti-rat IgG (Southern Biotechnology). This was followed by incubating with $A B C$ Vectastain elite reagent (Vector Laboratories, CA, USA) and finally the sections were stained with DAB reagent (Vector Laboratories, CA, USA) according to the manufacturer's instructions. Sections were counterstained with hematoxylin, and dehydrated in graded concentrations of alcohol and histolene before mounting in DPX (BDH, Poole, UK).

\section{Immunofluorescence}

HeLa cells were grown to about $30 \%$ confluency on cover slips followed by transient transfection with vectors encoding mouse Diablo. After $40 \mathrm{~h}$ cells were either exposed to UV $\left(25 \mathrm{~J} / \mathrm{M}^{2}\right)$ to induce UV radiationinduced apoptosis or left unexposed. Seven hours later all cells were incubated with Mito Tracker red (Molecular Probes) for $15 \mathrm{~min}$ at $37^{\circ} \mathrm{C}$ to stain the mitochondria before fixing in Histochoice (Amresco, Solon, $\mathrm{OH}$, USA) for $10 \mathrm{~min}$. Expression of Diablo was detected using $9 \mathrm{H} 10$ for $1 \mathrm{~h}$ followed by FITC labelled goat anti-rat (Southern Biotechnology). Nuclei were stained by adding DAPI, for $30 \mathrm{~min}$, together with the secondary antibody. Microscopy was performed on a confocal microscope (Leica Microsystems, Germany) visualizing mitochondria (as red), Diablo (as green) and nucleus (as blue).

\section{Acknowledgements}

We would like to acknowledge $L$ Cullen and $K$ Davern for assistance with antibody production, V Lapatis for assistance with confocal microscopy,
Dr. D Huang for providing valuable reagents and $\operatorname{Dr}(\mathrm{s})$. A Strasser, J Silke and PG Ekert for valuable technical advice. This work was supported by an NHMRC grant to the WEHI (Reg Key 973002) and by the Anti-Cancer Council of Victoria. DL Vaux is a scholar of the Leukemia and Lymphoma Society.

\section{References}

1. Hay BA, Wassarman DA and Rubin GM (1995) Drosophila homologs of baculovirus inhibitor of apoptosis proteins function to block cell death. Cell 83: $1253-1262$

2. Kaiser WJ, Vucic D and Miller LK (1998) The Drosophila inhibitor of apoptosis DIAP1 suppresses cell death induced by the caspase drICE. FEBS Lett. 440: 243-248

3. Wang SL, Hawkins CJ, Yoo SJ, Muller HA and Hay BA (1999) The Drosophila caspase inhibitor DIAP1 is essential for cell survival and is negatively regulated by HID. Cell $98: 453-463$

4. Song Z, Guan B, Bergman A, Nicholson DW, Thornberry NA, Peterson EP and Steller H (2000) Biochemical and genetic interactions between Drosophila caspases and the proapoptotic genes Rpr, Hid, and Grim. Mol. Cell. Biol. 20: 2907-2914

5. Du C, Fang M, Li Y, Li L and Wang X (2000) Smac, a mitochondrial protein that promotes cytochrome c-dependent caspase activation by eliminating IAP inhibition. Cell 102: 33-42

6. Verhagen AM, Ekert PG, Pakusch M, Silke J, Connolly LM, Reid GE, Moritz RL, Simpson RJ and Vaux DL (2000) Identification of DIABLO, a mammalian protein that promotes apoptosis by binding to and antagonizing IAP proteins. Cell 102: $43-53$

7. Verhagen AM, Silke J, Ekert PG, Pakusch M, Kaufmann H, Connolly LM, Day CL, Tikoo A, Burke R, Wrobel C, Moritz RL, Simpson RJ and Vaux DL (2002) HtrA2 promotes cell death through its serine protease activity and its ability to antagonise inhibitor of apoptosis proteins. J. Biol. Chem. 277: 445-454

8. Suzuki Y, Imai Y, Nakayama H, Takahashi K, Takio Kand Takahashi R (2001) A serine protease, HtrA2, is released from the mitochondria and interacts with XIAP, inducing cell death. Mol. Cell 8: 613-621

9. Hegde R, Srinivasula SM, Zhang Z, Wassell R, Mukattash R, Cilenti L, DuBois G, Lazebnik Y, Zervos AS, Fernandes-Alnemri T and Alnemri ES (2002) Identification of Omi/HtrA2 as a mitochondrial apoptotic serine protease that disrupts IAP-caspase interaction. J. Biol. Chem. 277: 432-438

10. Martins LM, laccarino I, Tenev T, Gschmeissner S, Totty NF, Lemoine NR, Savopoulos J, Gray CW, Creasy CL, Dingwall C and Downward J (2002) The serine protease $\mathrm{Omi} / \mathrm{Htr}$ 2 2 regulates apoptosis by binding XIAP through a Reaper-like motif. J. Biol. Chem. 277: 439-444

11. Chai J, Du C, Wu JW, Kyin S, Wang $X$ and Shi $Y(2000)$ Structural and biochemical basis of apoptotic activation by Smac/DIABLO. Nature 406: $855-$ 862

12. Liu Z, Sun C, Olejniczak ET, Meadows RP, Betz SF, Oost T, Herrman J, Wu JC and Fesik SW (2000) Structural basis for binding of Smac/DIABLO to the XIAP BIR3 domain. Nature 408: 1004-1008

13. Silke J, Verhagen AM, Ekert PG and Vaux DL (2000) Sequence as well as functional similarity for DIABLO/Smac and Grim, Reaper and Hid? Cell Death Differ. 7: 1275

14. Wu G, Chai J, Suber TL, Wu JW, Du C, Wang X and Shi Y (2000) Structural basis of IAP recognition by Smac/DIABLO. Nature 408: 1008-1012

15. Ekert PG, Silke J, Hawkins CJ, Verhagen AM and Vaux DL (2001) DIABLO promotes apoptosis by removing MIHA/XIAP from processed caspase 9 . J. Cell Biol. 152: 483-490

16. Srinivasula SM, Datta P, Fan XJ, Fernandes-Alnemri T, Huang Z and Alnemri ES (2000) Molecular determinants of the caspase-promoting activity of Smac/ DIABLO and its role in the death receptor pathway. J. Biol. Chem. 275: 3615236157

17. Hasegawa M, Wilson G, Russell LD and Meistrich ML (1997) Radiation-induced cell death in the mouse testis: relationship to apoptosis. Radiat. Res. 147: 457 467 
18. Moreno SG, Dutrillaux B and Coffigny H (2001) High sensitivity of rat foetal germ cells to low dose-rate irradiation. Int. J. Radiat. Biol. 77: 529-538

19. Adrain C and Martin SJ (2001) The mitochondrial apoptosome: a killerunleashed by the cytochrome seas. Trends Biochem. Sci. 26: 390-397

20. Abu-Qare AW and Abou-Donia MB (2001) Biomarkers of apoptosis: release of cytochrome c, activation of caspase-3, induction of 8-hydroxy-2'-deoxyguanosine, increased 3-nitrotyrosine, and alteration of p53 gene. J. Toxicol. Environ. Health B. Crit. Rev. 4: 313-332

21. Roy N, Deveraux QL, Takahashi R, Salvesen GS and Reed JC (1997) The c-IAP1 and C-IAP-2 proteins are direct inhibitors of specific caspases. EMBO J. 16: 6914-6925

22. Takahashi R, Deveraux Q, Tamm I, Welsh K, Assa-Munt N, Salvesen GS and Reed JC (1998) A single BIR domain of XIAP sufficient for inhibiting caspases. J. Biol. Chem. 273: 7787-7790

23. Deveraux QL, Leo E, Stennicke HR, Welsh K, Salvesen GS and Reed JC (1999) Cleavage of human inhibitor of apoptosis protein XIAP results in fragments with distinct specificities for caspases. EMBO J. 18: 5242-5251
24. Yoshikawa $H$, Nakajima $Y$ and Tasaka $K$ (2001) IFN-gamma Induces the Apoptosis of WEHI 279 and Normal Pre-B Cell Lines by Expressing Direct Inhibitor of Apoptosis Protein Binding Protein with Low pl. J. Immunol. 167: 2487-2495

25. Hinds MG, Norton RS, Vaux DL and Day CL (1999) Solution structure of a baculoviral inhibitor of apoptosis (IAP) repeat. Nat. Struct. Biol. 6: 648-651

26. Day CL, Dupont C, Lackmann M, Vaux DL and Hinds MG (1999) Solution structure and mutagenesis of the caspase recruitment domain (CARD) from Apaf-1. Cell Death Differ. 6: 1125-1132

27. O'Reilly LA, Cullen L, Moriishi K, O'Connor L, Huang DC and Strasser A (1998) Rapid hybridoma screening method for the identification of monoclonal antibodies to low-abundance cytoplasmic proteins. Biotechniques 25: 824-830

28. Print CG, Loveland KL, Gibson L, Meehan T, Stylianou A, Wreford N, de Kretser D, Metcalf D, Kontgen F, Adams JM and Cory S (1998) Apoptosis regulator bcl-w is essential for spermatogenesis but appears otherwise redundant. Proc. Natl. Acad. Sci. USA 95: 12424-12431 